TURIZAM

Volume 22, Issue 1

32-41 (2018)

ORIGINAL

SCIENTIFIC PAPER

\title{
Conflict and Tolerance in Urban Outdoor Recreation: A Case Study in Antalya and Berlin
}

\author{
Selcuk Sayan ${ }^{A}$, Dennis Kalisch ${ }^{B}$ \\ Received: March 2018 | Accepted: April 2018 \\ DOI: $10.5937 / 22-17512$
}

\begin{abstract}
Europe has become 'a continent of immigration' in the course of the last half century, and European societies have experienced growing ethnic and cultural diversity. Accordingly diverse social groups with various cultural backgrounds interact in everyday life. In this context, urban green spaces (UGS) provide opportunities and places for recreation, stress relief, interaction and encounters with other people. In contrast to a dense built environment of the cities, parks can be a platform for breaking social segregation. Personal characteristics of the users or visitors including cultural and socio-demographic background have been found to have an influence on outdoor recreation use patterns. Immigrants participate in recreation activities, but sometimes in different ways than members of the host community due to their diverse habits, preferences and different behaviour. However, little is known about these differences in recreation patterns in the urban environment particularly in Europe. Thus, the objective of the study is to a) explore urban outdoor recreation patterns of immigrants, b) investigate the interrelation between cultural background and recreation patterns and c) analyse the importance of UGS for visitors' encounters of different migration background in Antalya, Turkey and Berlin, Germany. Findings from qualitative interviews in both cities demonstrate that tolerance is the precondition for a successful integration into the host society. Respondents agreed that green spaces have a high potential for supporting the social integration process. Language can be a barrier and common interests are needed as a starting point for interaction. They agreed that the host community in both cities have a high willingness to accept foreigners.
\end{abstract}

Keywords: Urban green space, recreation, migrants, perception, tolerance

\section{Introduction}

Cultural diversity is an integrated component of the urbanisation process. Europe has become "a continent of immigration" in the course of the last half century, and European societies have experienced growing ethnic and cultural diversity (Okólski, 2012). The fact becomes even

A Independent researcher, Liselotte Herrmann Straße 26, 10407 Berlin. Corresponding author: selcuksayan66@gmail.com

B Technische Universität Berlin, Institute for Landscape Architecture and Environmental Planning, Chair in Landscape Economics, Berlin, dennis.kalisch@tu-berlin.de 
more relevant with the arrival of refugees from Middle East countries to European Union in 2015. International migration between continents receives significant global attention, and the largest numbers (72 million) reside in Europe (United Nations, 2014). Retirement migration also creates culturally diverse societies. International retirement migration is a new form of international human mobility which entails the movement of elder people in their later lives to the places with favourable characteristics in the pursuit of a better life (Balkır, Kırkulak, 2009).

As the population of the world becomes more urbanised particularly in Europe, negative impacts of modern living increase the importance of outdoor recreation which refers to activities that people undertake 'out of doors' in places where they can access nature or green areas, mainly as part of their daily or weekend routines (Bell et al., 2007). Most of the immigrants move to metropolitan areas and as a consequence European cities become multicultural places with diverse social groups interacting in the outdoors in everyday life. As urban green spaces are utilised for various recreation activities, the mixing of citizens with diverse ethnical backgrounds helps to avoid or reduce potential conflicts, ignorance and segregation (Nesdale, Todd, 200o).

Besides several economic and social challenges, the role of outdoor recreation on urban green spaces deserves consideration in the social inclusion of immigrants. Public spaces and particularly UGS serve as social arenas to provide opportunities for various outdoor recreation activities and places to encounter and meet people with different cultural backgrounds. In contrast to the densely populated environment of the inner cities, UGS such as parks, waterfront promenades, children playgrounds or beaches provide permanent recreation opportunities to relax and recreate and/or provide temporary events and entertainment opportunities such as festivals, markets or concerts to bring people together (Kaźmierczak, 2013). Therefore, green areas and outdoor recreation in the urban or rural context become increasingly important in contemporary society.

Studies in urban outdoor recreation demonstrated that, UGS are especially important for bringing people together, how public spaces facilitate inter-ethnic encounters and how these contacts effect individual's inclusion into society and well-being (Heringa et al., 2014). In this context especially children's playgrounds have been found to facilitate social interaction (Bennet et al., 2012). Socialising in UGS and participating in outdoor recreation activities are important in promoting the mixing of people with different ethnic backgrounds, both minority and majority populations (Gentin, 2011). Thus, participation of immigrants in outdoor recreation activities can be seen as an indicator of local community engagement (Aizlewood et al., 2006).

There is a long tradition of research on differences in outdoor recreation behaviour of ethnic groups in North America (see Gramann 1996 for an overview). Findings from early studies demonstrated that some minority-groups are underrepresented in wildland recreation. This focus changed from underutilisation to differences of recreation patterns between ethnic groups (Gobster, 2002, Das et al., 2017). Thereby, empirical studies found that black minorities have a lower participation rate than whites. This finding was explained with lower socioeconomic backgrounds of African Americans. However, it also demonstrated that participation differences between the groups persisted when socioeconomic variables were controlled, suggesting the sub-cultural preferences were also important in explaining variation in recreation patterns.

An increasing number of studies highlight the environmental and social benefits related to green space as being important to mitigate urbanisation-induced environmental effects and to increase the quality of life of citizens (Kabisch et al., 2015). Research on the social function of outdoor recreation has focused on multifunctional and intercultural integrative role 
of outdoor recreation and urban green spaces in a broader context (Madanipour, 1999; Germann-Chiari, Seeland, 2004; Dines, Cattell, 2006; Stack, Iwasaki, 2009; Jay, Schraml, 2009; Peters et al., 2010; Peters, de Haan, 2011; Peschardt et al., 2012; Kim, 2012; Horolets, 2012; Kivijärvi, 2015; Jay, Schraml 2014; Mata-Codesal et al., 2015).

These studies showed that people with different cultural background use the landscape differently for recreation since they have a variety of preferences and needs in the outdoor; urban green plays a significant role for everyday recreation activities; facilitates social inclusion, serves as a place for intercultural encounter, supports physical health and psychological well-being, stimulates to make contacts and foster social networks. Besides the positive outcomes, substantial conflict between groups or activities has been found in outdoor recreation (Manning, 2011).

Conflict is one of the complex consequences in outdoor recreation. Basically two theoretical conflict models are conceptualised: goal interference model and social values conflict model. The first model defines conflict as goal interference attributed to another's behaviour, in other words it is a special class of user dissatisfaction, where the cause of one's dissatisfaction is identified as another group or individual's behaviour (Jacob, Schreyer 1980). Accordingly four factor classes were derived which produce conflict in outdoor recreation namely activity style; resource specificity; mode of experience and lifestyle tolerance. In the second model, conflict is understood to arise from fundamentally different beliefs, values and norms held by alternative types of recreation users (Manning, 2011). There are distinctions between these models. However, 'lifestyle tolerance' factor of the goal interference model is closely related to social values model.

Except few studies which directly focus on the social values (Vaske et al., 1995; Carothers et al., 2001; Vaske et al., 2007), no studies examined the influence of socio-cultural characteristics on the recreation conflict. In fact habits, preferences and behaviours related with cultural traits may cause conflict among groups or among recreationists and managers. For example, the Tiergarten, a park in the city centre of, Berlin was highly used in the 1990's onwards by many cultural groups, majorly by Turkish descent migrants. As the park was overused for grilling, the inevitable result was an excessive amounts of litter. Conflicts among user groups and with managers ended up with the prohibition of grilling in Tiergarten in 2012. Many protests and tension occurred during and after the decision of prohibition. Thus, management of outdoor recreation should be conducted proactively, not reactively (Manning, Anderson, 2012).

Cultural differences in outdoor recreation and its influence on social inclusion in specific have received only limited research attention and these recent studies have basically examined the role and use of the green space for social inclusion. Findings from such studies have been mixed. A study on young Swiss and immigrants demonstrated that Zurich's public urban green spaces were found to play an important role for children and youths in making contacts and friends across cultures, which is considered a prerequisite for social inclusion (Seeland et al., 2009). Another study of people from various ethnic backgrounds in a mid-sized city, namely Nijmegen in The Netherlands, showed that being in parks together with people who are different from themselves is higher valued; however not many interactions occurred (Peters 2010). A confirmative second study from The Netherlands investigated the cross-cultural social interactions in three Dutch cities namely Utrecht, Haarlem and Arnhem. Results demonstrated that interactions were found to be cursory in the parks and particularly white native Dutch people do not look for more interactions while non-western migrants do; however, the latter do not take the initiative themselves (Peters et al., 2010). A study of local residents and recent immigrants' contact in Marzahn, Berlin demonstrated that various types of spac- 
es facilitate and support encounters ranging from superficial to fleeting, and these spaces hold different potentials for negotiating across differences and for countering prejudice and cultural racism (Matejskova, Leitner 2011). Most recently a study on the inner-city parks in Greater Manchester, UK found that these parks have full potential in supporting social interactions and developing social ties. These associations are existing between the qualities of the parks, the character of visits, and the extent of social ties in the neighbourhood (Kaźmierczak, 2013).

Other articles and studies agreed on the research gap in Europe and they suggested comparative case studies or international collaborations to improve scientific knowledge on social environment of immigrants, cultural differences in outdoor recreation and its relationship with social inclusion (Gentin, 2011; Jay et al., 2012; Kloek et al., 2015; Leikkilä et al., 2013; Kabisch et al., 2015). Finally, social research in outdoor recreation science showed that culture and demographics influence peoples' motivations, expectations and preferences in the outdoor recreation (Priskin, 2003, Fleishman et al., 2004; Sasidharan et al., 2005; Leujak, Ormond, 2007; Buijs et al., 2009; Sayan, Karagüzel, 2010; Sayan et al., 2013; Kabisch, Haase, 2014).

The majority of the studies in the previous paragraph are focused on specific cases, carried out with a limited number of respondents and mostly applied qualitative research methods. Some studies are cautious about making general assumptions for the whole community while others are overoptimistic. Previous research also demonstrated that there is a research trend for the social function of the UGS in Europe. However comprehensive and in-depth studies are still limited in the German context which has always been an attractive country for immigrants.

\section{Methods and data}

We initiated two pilot studies in Turkey and Germany to explore the social and cultural dimensions of urban outdoor recreation and the potential opportunities of everyday recreation for the social inclusion of migrants in both cases. The main idea of our research approach is that interviewing German migrants in Antalya and Turkish migrants in Berlin is expected to be more fruitful and language barrier-free with native researchers.

The study was carried out in Antalya, Turkey and Berlin, Germany. Antalya is a popular destination for German migrants. Around 40,00o German and German speaking immigrants live in the Province of Antalya and the majority are retired people. It is a popular holiday destination for German tourists as well. Berlin, as being the capital city of Germany, is known as the largest Turkish settlement in one city outside Turkey. Migrants with a Turkish descent are the largest ethnic minority group in Berlin with a population of around 231,00o (Microcensus Berlin, 2016). The study was initiated in two cases and carried out in two parts (three months each): first in Antalya (September-November/2014) and second in Berlin (June-August/2015).

A multi-method approach incorporating focus group meeting and interviews were implemented. In cooperation with DTF (Mediterranean Friendship and Cultural Association) we organised a focus group meeting in Antalya with nine members of the German speaking community to gather in-depth information about the recreation behaviour and perceptions of German speaking migrants in Antalya. This step was followed by five semi-structured qualitative interviews with German migrants permanently living in Antalya. The purpose of the interviews is to get insights into everyday recreation patterns, preferences for activities, perceptions of potential conflicts between recreationists and willingness to tolerate the behaviour of other people. Thereby the questions for the guided interviews focused on motives, perceptions and preferences of German speaking inhabitants in Antalya. 
The Berlin case study was implemented by interviews with stakeholders and experts of three relevant social and environmental NGOs. In a following step we conducted eight qualitative interviews by using the adapted version of the questions that was previously used in Antalya. The semi-structured interviews lasted between 75 and 105 minutes and respondents were free to choose German or Turkish languages. Sometimes we interviewed simultaneously in two languages, and collected, in-depth data without any language barrier. Some opinions were articulated in the native language and some in German.

The interviews were conducted under six main topics and various questions were asked. The generic interview sheet which is applied in both case studies are shown on Table 1.

Table 1. Semi-structured interview sheet

\begin{tabular}{|c|c|c|}
\hline \# & Interview topic & Interview questions \\
\hline 1 & $\begin{array}{l}\text { Everyday outdoor recreation } \\
\text { behaviour }\end{array}$ & $\begin{array}{l}\text { - Importance of recreation in the daily routine, } \\
\text { - Typical everyday outdoor recreation trip (mobility; places to visit; time; } \\
\text { - Mostion; group characteristics), } \\
\text { - } \text { Provision of services and infrastructure, } \\
\text { - Level of satisfaction with existing services, } \\
\text { - Constraints for outdoor recreation. }\end{array}$ \\
\hline 2 & $\begin{array}{l}\text { Demand for weekend trips in } \\
\text { the surrounding countryside }\end{array}$ & $\begin{array}{l}\text { - Weekend excursions (frequency, places; time, duration) } \\
\text { - Importance and highlights of an excursion, } \\
\text { - Constraints for weekend excursions. }\end{array}$ \\
\hline 3 & $\begin{array}{l}\text { Individual recreation } \\
\text { preferences }\end{array}$ & $\begin{array}{l}\text { - Likes and dislikes at green spaces in general, } \\
\text { - Missing attributes of the visited places, } \\
\text { - Preferred recreation facilities and infrastructure, } \\
\text { - Cultural differences of preferences in outdoor recreation between } \\
\text { Turkish and German people. }\end{array}$ \\
\hline 4 & $\begin{array}{l}\text { Recreation behaviour and } \\
\text { cultural background }\end{array}$ & $\begin{array}{l}\text { - Cultural differences of behaviour } \\
\text { - Differences in recreation patterns }\end{array}$ \\
\hline 5 & Tolerance & $\begin{array}{l}\text { - Likes and dislikes of behaviour in the parks, } \\
\text { - Tolerance for an unwanted behaviour, } \\
\text { - Feeling comfortable in the parks. }\end{array}$ \\
\hline 6 & Recreation and social inclusion & $\begin{array}{l}\text { - Potential of green spaces for social inclusion, } \\
\text { - Interaction with local people in the parks, } \\
\text { - Type of any discrimination in green spaces. }\end{array}$ \\
\hline
\end{tabular}

According to the research design, a category-based analysis of the qualitative interviews was employed. Category-based analysis is a qualitative text analysis. The main topics which serve as analysis categories are derived directly from research questions (Kuckartz, 2014).

\section{Results and discussion}

We derived five categories from the interview transcription namely migration groups, recreation behaviour, perceptions, conflicts and potential for inclusion/socialising. We analysed the interviews; determined the topics which are addressed in the given passage of text and assigned them to the appropriate category. In every category, common facts and issues were coded and summarized as in Table 2.

Main findings are listed and further explained in the following bullet points concerning the content, target groups and the research design: 
Table 2. Analysis of the case studies

\begin{tabular}{|c|c|c|}
\hline Categories & Antalya case study & Berlin case study \\
\hline Migration groups & $\begin{array}{l}\text { - Amenity-driven migrants } \\
\text { - Majority is retired people from } \\
\text { Germany } \\
\text { - Residence at two places }\end{array}$ & $\begin{array}{l}\text { - Labour migrants and descendants } \\
\text { - Largest immigrant group in Berlin } \\
\text { - Major residence is Germany } \\
\text { - Regular homeland visits }\end{array}$ \\
\hline Recreation behaviour & - Use of UGS on regular basis & $\begin{array}{l}\text { - Use of UGS on regular basis, but } \\
\text { depending on lifestyle }\end{array}$ \\
\hline Perceptions & $\begin{array}{l}\text { "Germans" have different preferences } \\
\text { than Turkish people in terms of } \\
\text { activities (sports) and behaviour } \\
\text { (solitude, relaxation, lower tolerance } \\
\text { for noise and crowding) }\end{array}$ & $\begin{array}{l}\text { - "Turks" or "Turkish descent migrants" } \\
\text { have different preferences than } \\
\text { Germans in terms of activities } \\
\text { (picnicking, barbecue) and patterns } \\
\text { (larger groups, higher tolerance for } \\
\text { noise and crowding) }\end{array}$ \\
\hline Conflicts & $\begin{array}{l}\text { - Litter on urban green spaces and at the } \\
\text { beaches }\end{array}$ & - Litter and dog turds in public parks \\
\hline $\begin{array}{l}\text { Potential for inclusion } \\
\text { and socializing }\end{array}$ & $\begin{array}{l}\text { - High willingness to integrate into host } \\
\text { society } \\
\text { - Host community has a high level of } \\
\text { acceptance for foreigners } \\
\text { - Common interests needed as a starting } \\
\text { point } \\
\text { - Language as a barrier for interaction } \\
\text { - "Drink related" socialising }\end{array}$ & $\begin{array}{l}\text { - High tolerance of Berlin inhabitants; } \\
\text { but discrimination and prejudice exist } \\
\text { - High potential for social inclusion (i.e. } \\
\text { playgrounds) } \\
\text { - Language could be a barrier for the first } \\
\text { generation } \\
\text { - "Food related" socialising }\end{array}$ \\
\hline
\end{tabular}

- Tolerance is the precondition for living in foreign countries and a successful inclusion into the host society. Although both group of respondents mentioned that cultural differences exist for the preferences of outdoor recreation activities, particularly German migrants in Antalya agreed that the host community has a high willingness to accept foreigners and are helpful in general. Turkish interviewees in Berlin mentioned that local people are in general respectful and tolerant in the outdoors. However some prejudice on other cultures and/or wear headscarves still exist.

- UGS are places for encounters and communication with other people. Respondents in both cities agreed that these areas have a high potential for supporting the social inclusion process. However they also stated that a) language is a barrier for interaction and b) common interests are needed as a starting point.

- Germans and the German speaking community in Antalya represent a typical example of retirement migration. Although middle-aged promoters for small businesses and tourism-related employees are part of the group, retired migrants in Antalya still form the major part of the German community. Most of them are amenity-driven migrants who live in both countries and many of themdepending on the German health care system..

- Turkish descent migrants in Germany in general represent a typical example of labour migration which is driven by economic reasons. Turkish migration to Germany dates back more than 50 years to labour-recruitment agreements made in the early 1960 s (King, K1lıc, 2014). As being the largest immigrant group in Germany, Turkish descent migrants have always been a topic. The respondents we interviewed were living and working in Berlin and having contact with their homeland mostly during their holidays.

- Asymmetric conflicts exist between different user groups based on activities in the park and preferences for park conditions. Major complaints of German migrants in Antalya is litter at urban green spaces and beaches which has direct influence on the quality of 
recreation experience. Turkish descent migrants in Berlin also complained about litter. However major conflict with them is dog turds in the parks and on the streets.

- We explored that a cultural group is composed of several sub-groups, e.g. the German community in Antalya demonstrate variation in migration motivation (retirement, work, climate, etc.), generation, life expectancy, etc. On the other hand German natives and/or German speaking Turkish descent migrants would also demonstrate variation for the needs or expectancies. The Turkish community in Berlin demonstrates variation in ethnicity, life style and ideology. In this sense German community in Antalya supposed to be a culturally homogeneous group, vice versa the Turkish community in Berlin was found to be culturally heterogeneous.

The research demonstrated that Germans or German speaking community in Antalya and Turkish descent migrants in Berlin have different drivers and motivations for being migrants. Therefore a comparative final analysis would not be appropriate. In general cultural groups are heterogeneous and there might be sub-groups which demonstrate different patterns of use which should be addressed and represented for inclusive studies. Even the non-participants should be investigated to find out the reasons for their exclusion. Thus, sampling is highly important to represent the all community, and to generalize the results for the whole group.

Qualitative research methods have limitations concerning representation and the sample size. Mixed methods approach incorporating quantitative and qualitative research would better facilitate the representation of sub-groups than collecting data only by qualitative methods. The case studies in Antalya and Berlin demonstrate that the data provided by qualitative research methods feature personal opinions of a limited number of respondents. Therefore we concluded that future studies applying qualitative methods would be either limited or specific that is confirmed by previous studies. Main purpose of many relevant studies (Seeland et al., 2009; Peters, 2010; Peters et al., 2010; Matejskova, Leitner 2001; Kaźmierczak, 2013) which are carried out only with qualitative methods is not generalisation but to provide a rich and in-depth personal experience. However results of such studies could be used for implications by local governments or some interest groups which may not help to solve potential conflicts in general.

Motivations for an outdoor recreation activity depend on many things. Priorities, recreation needs and expected outcomes would be different for a couple and a big family group including relatives and children for example. Each of the motivating factors would have an influence on the preferences, conflicts and expectations in outdoor recreation and consequently social inclusion. Particularly the existing conflicts in Antalya is generated by the other group or individual's behaviour and in Berlin by different beliefs, values and norms held by alternative types of recreation users. However the distinction between two types of conflict is not clear to fit into and explain with Jacob and Schreyer's (1980) two conflict models.

\section{Conclusion}

Urban green spaces are important places for recreation and offer opportunities to encounter people with different cultural backgrounds. Respondents indicated that the host community have a high willingness to accept foreigners and are helpful. However they also mentioned that cultural differences exist in everyday outdoor recreation. Results from Antalya and Berlin demonstrated that tolerance is the precondition for living in foreign countries and a successful integration into the host society. Respondents agreed that these areas have a high poten- 
tial for supporting the social integration process, but they also stated that a) language is a barrier for interaction and b) common interests (e.g. children, dogs or sports etc.) are needed as a starting point. For example, the participation rate of migrants in outdoor recreation and sport activities could be an indicator of one's local community engagement. There is a trend in Berlin to implement intercultural gardens to boost these interactions. The representation of sub-groups and non-participants is important for an inclusive study to find out the reasons of exclusion and displacement. To evaluate this research gap, we recommend a mixed methods approach incorporating quantitative and qualitative research to better facilitate the representation of sub-groups. Study findings can be used to inform urban planning policies and decisions on urban green space development in both cities. Also landscape planning is more and more focussing on the social functions of urban green spaces and implementing these topics into political frameworks. Further research should focus on the potential of outdoor recreation for social inclusion particularly need to clarify conflict in urban outdoor recreation in culturally diverse cities. In addition, knowledge about recreation habits of migrants and the host community can provide useful information for the management of urban green spaces.

\section{Acknowledgements}

The funding support provided by DFG (Deutsche Forschungsgemeinschaft) is gratefully acknowledged.

\section{References}

Aizlewood, A., Bevelander, P., Pendakur, R. 2006. Recreational Participation Among Ethnic Minorities and Immigrants in Canada and the Netherlands. Journal of Immigrant E Refugee Studies 4(3), 1-32.

Balkır, C., Kırkulak, B. 2009. Turkey, the new destination for international retirement migration. In: Migration and Mobility in Europe: Trends, Patterns and Control (Eds. H. Fassmann, M. Haller and D. Lane), Edward Elgar Publishing Limited, UK, 123-143

Bell, S., Tyrväinen, L., Sievänen, T., Pröbstl, U., Simpson, M. 2007. Outdoor recreation and nature tourism: A European perspective. Living Reviews in Landscape Research 1(2), 1- 46.

Bennet, S.A., Yiannakoulias, N., Williams, A.M., Kitchen, P. 2012. Playground accessibility and neighbourhood social interaction among parents. Social indicators research 108(2), 199-213.

Buijs, A.E., Elands, B., Langers, F. 2009. No wilderness for immigrants: cultural differences in images of nature and landscape preferences. Landscape and Urban Planning 91 (3), 113-123.

Carothers, P., Vaske, J.J., Donnelly, M.P. 2001. Social Values versus Interpersonal Conflict among Hikers and Mountain Bikers. Leisure Sciences 23, 47-61.

Das, K. V., Fan, Y., French, S. A. 2017. Park-use behavior and perceptions by race, Hispanic origin, and immigrant status in Minneapolis, MN: implications on park strategies for addressing health disparities. Journal of immigrant and minority health 19(2), 318-327.

Dines, N., Cattell, V. 2006. Public spaces, social relations and well-being. Bristol, UK: The Policy Press.

Fleishman, L., Feitelson, E., Salomon, I. 2004. The role of cultural and demographic diversity in crowding perception: evidence from nature reserves in Israel. Tourism Analysis 9,23-40 
Gentin, S., 2011. Outdoor recreation and ethnicity in Europe: A review. Urban Forestry $\mathcal{E}$ Urban Greening 10, 153-161.

Germann-Chiari, C., Seeland, K. 2004. Are urban green spaces optimally distributed to act as places for social integration? Results of a geographical information system (GIS) approach for urban forestry research. Forest Policy and Economics 6, 3-13.

Gobster, P. H. 2002. Managing urban parks for a racially and ethnically diverse clientele. Leisure sciences 24(2), 143-159.

Gramann, J. 1996. Ethnicity, Race, and Outdoor Recreation: A Review of Trends, Policy, and Research. Final Report R-96-1. Department of Recreation, Park, and Tourism Sciences: Texas A\&M University.

Heringa, A., Bolt, G., Dijst, M., Van Kempen, R. 2014. Individual Activity Patterns and the Meaning of Residential Environments for Inter-ethnic Contact. Tijdschrift voor Economische en Sociale Geografie 105, 64-78.

Horolets, A. 2012. Migrants' leisure and integration. Report. Institute of Public Affairs:Instytut Spraw Publicznych, Warszaw.

Jacob, G.R., Schreyer, R. 1980. Conflict in Outdoor Recreation: A Theoretical Perspective. Journal of Leisure Research 12, 368-380.

Jay, M., Schraml, U. 2009. Understanding the role of urban forests for migrants - uses, perception and integrative potential. Urban Forestry \& Urban Greening 8, 283-294.

Jay, M., Peters, K., Buijs, A.E., Gentin, S., Kloek, M.E., O’Brien, L. 2012. Towards access for all? Policy and research on access of ethnic minority groups to natural areas in four European countries. Forest Policy and Economics 19, 4-11.

Jay, M., Schraml, U. 2014. Diversity in mind: Towards a differentiated understanding of migrants' recreational practices in urban forests. Urban Forestry and Urban Greening 13(1), 38-47.

Kabisch, N., Haase, D. 2014. Green justice or just green? Provision of urban green spaces in Berlin, Germany. Landscape and Urban Planning 122, 129-139.

Kabisch, N., Qureshi, S., Haase, D. 2015. Human-environment interactions in urban green spaces - A systematic review of contemporary issues and prospects for future research. Environmental Impact Assessment Review 50, 25-34.

Kaźmierczak, A. 2013. The contribution of local parks to neighbourhood social ties. Landscape and Urban Planning 109, 31-44.

Kim, J. 2012. Exploring the Experience of Intergroup Contact and the Value of Recreation Activities in Facilitating Positive Intergroup Interactions of Immigrants. Leisure Sciences 34, 72-87.

Kivijärvi, A. 2015. Fragility of leisure ties between ethnic minority and majority youth - an empirical case from Finland. Leisure Studies 34, 150-165.

Kloek, M., Peters, K., Wagner, L. 2015. Reflections on measuring discrimination: The case of outdoor recreation. Tijdschrift voor Economische en Sociale Geografie 106(3), 353-358.

Kuckartz, U. 2014. Qualitative Text Analysis. SAGE Publications Ltd., London.

Leikkilä, J., Faehnle, M., Galanakis, M. 2013. Promoting interculturalism by planning of urban nature. Urban Forestry \& Urban Greening 12, 183-190.

Leujak, W., Ormond, R. 2007. Visitor perceptions and the shifting social carrying capacity of south Sinai's coral reefs. Environmental Planning 39,472-489.

Madanipour, A. 1999. Why are the design and development of public spaces significant for cities? Environment and Planning B Planning and Design 26, 879-891. 
Manning, R., 2011. Studies in outdoor recreation: Search and research for satisfaction. Oregon State University Press, Corvallis.

Manning, R.E., Anderson, L.E. 2012. Managing Outdoor Recreation: Case Studies in the National Parks. CABI, UK

Mata-Codesal, D., Peperkamp, E., Tiesler, N.-C. 2015. Migration, migrants and leisure: meaningful leisure?. Leisure Studies 34(1), 1-4.

Matejskova, T., Leitner, H. 2011. Urban encounters with difference: the contact hypothesis and immigrant integration projects in eastern Berlin. Social \& Cultural Geography 12 (7), 717741.

Microcensus Berlin. 2016. Statistical Report. Results from Mikrozensus in Berlin 2015. Amt für Statistik Berlin-Brandenburg (in German).

Nesdale, D., Todd, P., 20oo. Effect of contact on intercultural acceptance: a field study. International Journal of Intercultural Relations 24, 341-360.

Okólski, M. 2012. European Immigrations: Trends, Structures and Policy Implications. Amsterdam University Press, Amsterdam.

Peschardt, K.K., Schipperijn, J., Stigsdotter, U.K. 2012. Use of Small Public Urban Green Spaces (SPUGS). Urban Forestry \& Urban Greening 11, 235-244

Peters, K. 2010. Being Together in Urban Parks: Connecting Public Space, Leisure, and Diversity. Leisure Sciences 32, 418-433.

Peters, K., Elands, B., Buijs, A. 2010. Social interactions in urban parks: Stimulating social cohesion?. Urban Forestry and Urban Greening 9, 93-100.

Peters, K., de Haan, H. 2011. Everyday spaces of inter-ethnic interaction: the meaning of urban public spaces in the Netherlands. Leisure/Loisir 35, 169-19o.

Priskin, J. 2003. Tourist perceptions of degradation caused by coastal nature-based recreation. Environmental Management 32(2), 189-204.

Sasidharan, V., Willits, F., Godbey, G. 2005. Cultural differences in urban recreation patterns: an examination of park usage and activity participation across six population subgroups. Managing Leisure 10, 19-38.

Sayan, S., Karagüzel, O. 2010. Problems of outdoor recreation: the effects of visitors' demographics on the perception of Termessos National Park, Turkey. Environmental Management 45, 1257-1270.

Sayan, S., Krymkowski, D.H., Manning, R.E., Valliere, W.A., Rovelstad, E.L. 2013. Cultural Influence on Crowding Norms in Outdoor Recreation: A Comparative Analysis of Visitors to National Parks in Turkey and the United States. Environmental Management 52, 493-502.

Seeland, K., Dübendorfer, S., Hansmann, R. 2009. Making friends in Zurich's urban forests and parks: The role of public green space for social inclusion of youths from different cultures. Forest Policy and Economics 11, 10-17.

Stack, J., Iwasaki, Y. 2009. The role of leisure pursuits in adaptation processes among Afghan refugees who have immigrated to Winnipeg, Canada. Leisure Studies 28, 239-259.

United Nations, 2014. International migration and development. Report of the Secretary-General $A / 69 / 207$.

Vaske, J.J., Donnelly, M.P., Wittmann, K., Laidlaw, S. 1995. Interpersonal versus social-values conflict. Leisure Sciences 17,205-222.

Vaske, J.J., Needham, M.D., Cline Jr,R.C. 2007. Clarifying Interpersonal and Social Values Conflict among Recreationists. Journal of Leisure Research 39(1), 182-195. 